\title{
Depth persistence of the spatial pattern of soil-water storage along a small transect in the Loess Plateau of China
}

\author{
Xuezhang Li ${ }^{\mathrm{a}, \mathrm{b}, \mathrm{c}}$, Ming'an Shao ${ }^{\mathrm{c}, *}$, Xiaoxu Jia ${ }^{\mathrm{c}}$, Xiaorong Wei ${ }^{\mathrm{d}}$, Liang $\mathrm{He}^{\mathrm{e}}$ \\ ${ }^{a}$ Key Laboratory for Agro-Ecological Processes in Subtropical Region, Institute of Subtropical Agriculture, Chinese Academy of Sciences, Changsha 410125, China \\ ${ }^{\mathrm{b}}$ Huanjiang Observation and Research Station for Karst Ecosystem, Chinese Academy of Sciences, Huanjiang 547100, China \\ ${ }^{\mathrm{c}}$ Key Laboratory of Ecosystem Network Observation and Modeling, Institute of Geographic Sciences and Natural Resources Research, Chinese Academy of Sciences, Beijing \\ 100101, China \\ ${ }^{\mathrm{d}}$ State Key Laboratory of Soil Erosion and Dryland Farming on the Loess Plateau, Northwest A E' F University, Yangling 712100, China \\ ${ }^{\mathrm{e}}$ Key Laboratory of Water Cycle E Related Land Surface Processes, Institute of Geographic Sciences and Natural Resources Research, Chinese Academy of Sciences, Beijing \\ 100101, China
}

\section{A R T I C L E I N F O}

\section{Article history:}

Received 20 July 2014

Received in revised form 1 August 2015

Accepted 20 August 2015

Available online 28 August 2015

This manuscript was handled by

Konstantine P. Georgakakos, Editor-in-Chief, with the assistance of Venkat Lakshmi, Associate Editor

\section{Keywords:}

Depth persistence

Soil-water storage

Spatial pattern

Wavelet coherency

The Loess Plateau

\begin{abstract}
S U M M A R Y
Knowledge of the spatial patterns of soil-water storage (SWS) in soil profiles is important for understanding the dynamics of soil water between surface and subsurface soil layers in semiarid area. We investigated the depth persistence of the overall and scale-specific spatial patterns of SWS for different soil layers during different seasons. Soil-water contents were measured using a neutron probe on 22 occasions in 2012 and 2013 along a 1340-m transect over several sub-watersheds in the Liudaogou catchment on the Loess Plateau of China. Similarities in the spatial patterns of SWS were analyzed by Spearman's rank correlations and wavelet coherency. A spatiotemporal analysis indicated that the temporal evolution of the SWS profiles differed between the growing and non-growing seasons and that landscape position and soil texture determined the amount of SWS at each sampling location. Spearman's rank correlations were significant between any two layers within different seasons, and the correlation coefficients decreased as the distance between layers increased. Clay content controlled the spatial pattern of SWS between layers at large scales. The SWS spatial pattern had a higher depth persistence during the non-growing season than during the growing season, and the soil layer had a larger effect than season on the similarity in SWS spatial patterns. These results can improve our understanding of the hydrological processes in soil profiles and can be of considerable value in the application of hydrological models and in water management.
\end{abstract}

(ㄷ) 2015 Elsevier B.V. All rights reserved.

\section{Introduction}

Soil-water content is a key variable in many hydrological and biological processes (Entin et al., 2000; Western et al., 2004; Brocca et al., 2009). It is also a limiting factor in crop production and/or vegetational restoration in arid and semi-arid regions, such as the Chinese Loess Plateau (Hu et al., 2009, 2010). Most recent studies have emphasized soil moisture at shallow depths (Starks et al., 2006; Cosh et al., 2008; Brocca et al., 2009; Zhao et al., 2010; Zhang and Shao, 2013), but some, for example Gao and Shao (2012b), have studied the temporal stability of soil-water storage (SWS) in soil layers as deep as $3 \mathrm{~m}$. Wang et al. (2010)

\footnotetext{
* Corresponding author. Fax: +86 2987012210.

E-mail address: shaoma@igsnrr.ac.cn (M. Shao).
}

investigated the dynamic characteristics of dried soil layers within profiles $6 \mathrm{~m}$ deep on the Loess Plateau. Obtaining soil-water data is more difficult for deep than for shallow soils. The characteristics of hydrological processes in deep soil and the relationships with plants, soil properties, and topography are thus relatively poorly known but are necessary for the application and verification of hydrological models (Western et al., 2002; Koster et al., 2004). Information characterizing the soil-water dynamics in various layers is also helpful for developing hydrological models for monitoring water, especially in areas with deep soils.

Soil-water content varies in both space and time due to the heterogeneity and combinations of the controlling factors. The storage of soil water, however, can present persistent spatial patterns over time (Grayson and Western, 1998; Cassel et al., 2000; Mohanty and Skaggs, 2001; Lin, 2006; Brocca et al., 2009, 2010; 
Zhao et al., 2010). Vachaud et al. (1985) first introduced this phenomenon as the temporal stability of SWS. Many studies have subsequently examined the temporal stability of soil water for various land uses (Vachaud et al., 1985; Lin, 2006; Jia and Shao, 2013; Liu and Shao, 2014), climatic areas (Jacobs et al., 2004; Hu et al., 2009, 2010), scales (Gao and Shao, 2012a,b; Hu et al., 2010), and topographies (Grayson et al., 2002; Hébrard et al., 2006). Temporal stability can be recognized as similarities of spatial patterns of soil water along time series. Similarly, the persistence of a spatial pattern of soil water along a depth series has been termed depth persistence. Little information about the similarity or persistence of SWS spatial patterns at various depths over time, however, is available for the Loess Plateau. Further investigation of the relationships among the soil-water contents in various layers in this semiarid area would improve our understanding of the vertical soil-water dynamics.

The Loess Plateau of China is known for its uniquely deep loessial soil, intense soil erosion, and degradation of the vegetation ( $\mathrm{Hu}$ et al., 2009, 2010). It is characterized by many deep gullies and undulating loessial slopes, which produce highly spatially variable soil-water contents (Hu et al., 2009; Wang et al., 2012). The wet (growing) and dry (non-growing) seasons in this region are clearly separated (Jia et al., 2012), and the different conditions of wetness can differentially affect hydrological processes (Vachaud et al., 1985; Lin, 2006; Gao et al., 2011). For example, Gao et al. (2011) found that the temporal stability of spatial patterns of soil water in the root-zone in jujube orchards was higher in either the dry or wet season than for both seasons together. Lin (2006) showed that the temporal stability of soil water varied between drydown and wet-up periods in complex terrains. The spatial patterns of SWS profiles can differ between the growing and non-growing seasons due to differences in the vegetation and soil wetness. Few reports, however, have addressed these differences on the semiarid Loess Plateau with its complex terrains, soil types, and plant covers. Furthermore, plant growth can also control SWS spatial patterns, because the root structure and vegetational cover affect the evapotranspiration and storage of water (Zhao et al., 2010; Jia et al., 2013b). Jia et al. (2013a,b) showed that the temporal stability of hillslope-scale SWS profiles was strongly controlled by aboveground biomass and litterfall in a small watershed on the Loess Plateau. The type of vegetation can also significantly affect the temporal stability of soil-water spatial patterns (Jia and Shao, 2013).

Spearman's rank correlation analysis is widely used to identify overall similarity at measurement scale. Kachanoski and de Jong (1988), however, found that the spatial patterns of SWS were scale-dependent for hydrological processes operating at different spatial scales. Wavelet coherency based on wavelet transformation has thus been used to determine the correlations between two variables at different scales and locations, because it can resolve the variability of the data in the spatial series. For example, Biswas and Si (2011c) used wavelet coherency to study the scaleand location-specific temporal stability of SWS between sampling occasions in a hummocky area. Wavelet coherency has also been used to examine the scale- and location-specific variations between two soil properties (Si and Zeleke, 2005; Yates et al., 2007; Biswas and Si, 2011b). The spatial patterns of SWS between surface and subsurface soils on the Loess Plateau, however, have not been analyzed using wavelet coherency. The specific objectives of the present study were thus (1) to investigate the spatial patterns of SWS within profiles along a 1340-m transect in a typical semiarid catchment on the Loess Plateau and (2) to assess the dependence of the similarities of the spatial patterns of SWS on soil depth and season. The overall and scale-dependent similarities of the spatial patterns of SWS were identified using Spearman's rank correlation and wavelet coherency analyses, respectively.

\section{Materials and methods}

\subsection{Study area}

The study was conducted in the Liudaogou watershed $\left(110^{\circ} 21^{\prime}-\right.$ $\left.110^{\circ} 23^{\prime} \mathrm{E}, 38^{\circ} 46^{\prime}-38^{\circ} 51^{\prime} \mathrm{N}\right)$ in Shenmu County on the northern Loess Plateau of China (Fig. 1). The study area covers $6.89 \mathrm{~km}^{2}$ and is in the transitional belt between the Loess Plateau and the $\mathrm{Mu}$ Us desert. The landform is undulating with an elevation of $1056-1130 \mathrm{~m}$ a.s.l. The climate is moderate semiarid with a mean annual temperature of $8.4{ }^{\circ} \mathrm{C}$ and a mean annual rainfall of $437 \mathrm{~mm}$, more than $70 \%$ of which falls from June to September (Fig. 2). According to the growth of vegetation, the entire year can be divided into growing season (from May to October) and non-growing season (from November to April). The primary soil types are Aeolian sandy soils and Ust-Sandlic Entisol soils. The dominant vegetation includes purple alfalfa (Medicago sativa L.), Korshinsk peashrub (Caragana korshinskii Kom.), and bunge needlegrass (Stipa bungeana Trin.). A representative sampling transect with 135 locations at regular intervals of $10 \mathrm{~m}$ (Fig. 1) was established in July 2012 in an east-west direction for sampling areas with the dominant soil types, landforms, and vegetation. An aluminum neutron-probe access tube was installed at each location for measuring soil-water content at 15 depths. For most sampling locations, soil-water content can be measured to the maximum depth of $3.0 \mathrm{~m}$. However, soil moisture data for a few sampling locations can only be derived to a depth of $1.2 \mathrm{~m}$ due to the presence of bedrock below that depth.

\subsection{Sampling and measurements}

\subsubsection{Measurement of SWS}

Soil-water contents were measured with a neutron probe (Beijing Super Power Company, Beijing, China) at each location from 23 August 2012 to 28 October 2013. Samples were measured on 22 occasions during the study period, and we analyzed the data from four randomly selected sampling occasions for both the growing and non-growing seasons. Twelve locations with different water conditions were selected to establish calibration curves following procedure introduced by Hu et al. (2010). Volumetric soilwater content, $\theta$, was calculated using the calibration equation:

$\theta=0.6565 C R-0.0068 \quad\left(R^{2}=0.9031, P<0.001\right)$

where $C R$ is the slow-neutron counting rate.

Following Jia and Shao (2013), SWS at a specific depth can be calculated as:

$S=\theta \times h \times 2 \times 10$

where $S$ is the SWS at a specific depth ( $\mathrm{mm}), \theta$ is the volumetric water content at this depth $\left(\mathrm{cm}^{3} \mathrm{~cm}^{-3}\right)$, and $h$ is the soil-depth interval $(20 \mathrm{~cm})$.

\subsubsection{Measurement of other soil parameters}

Sampling locations and the corresponding site elevations were determined by a GPS receiver with a 5-m resolution. Undisturbed soil samples for measurements of saturated soil hydraulic conductivity (Ks) using the constant-head method (Klute and Dirksen, 1986) and of soil bulk density were collected at each sampling location $0.2 \mathrm{~m}$ from the access tube using a cutting ring $5 \mathrm{~cm}$ in height. Disturbed soil samples were divided into two sub-samples and air-dried. One sub-sample was passed through a $0.25-\mathrm{mm}$ sieve for the determination of soil organic-carbon (OC) content by the dichromate oxidation method (Nelson and Sommers, 1982). The other sub-sample was passed through a 1-mm sieve to analyze soil-particle sizes using a Mastersizer2000 

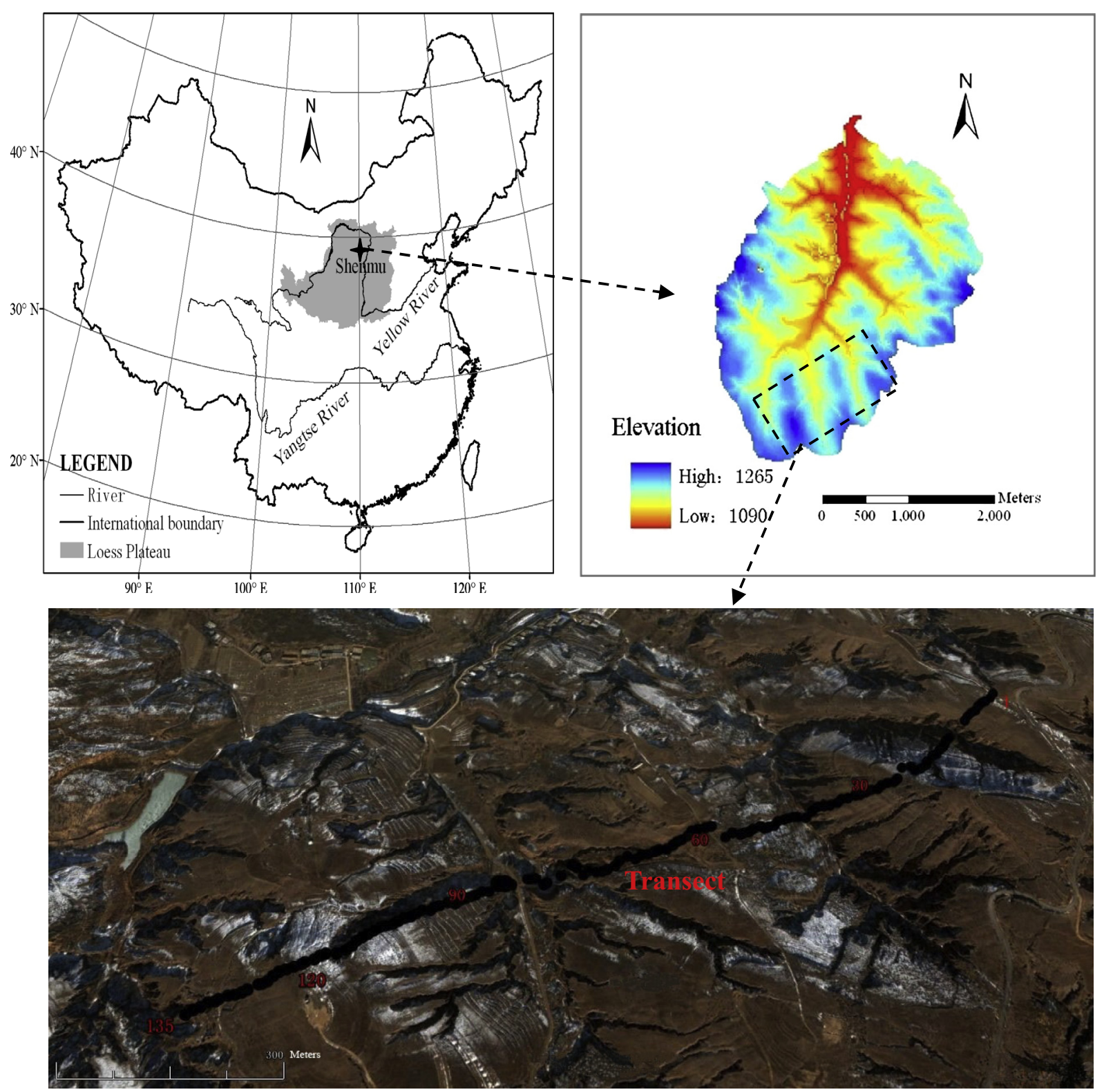

Fig. 1. Location of the study area in Shenmu County and the transect in the Liudaogou watershed on the Loess Plateau in northwestern China.

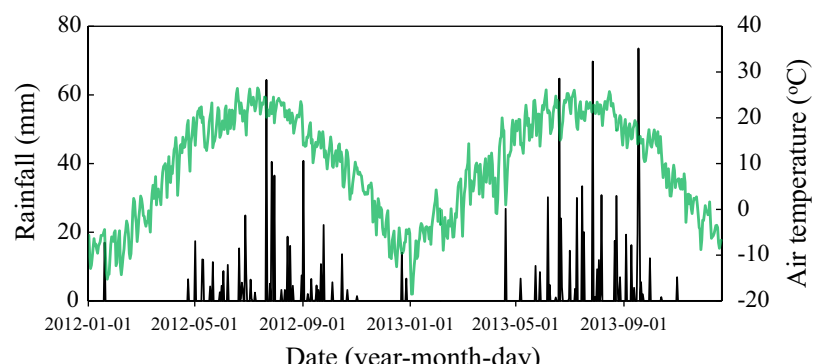

Fig. 2. Evolution of daily rainfall and mean air temperature in 2012-2013.

(Malvern Instruments, Malvern, England). In September 2013, we measured peak aboveground biomass clipped from a $1 \times 1 \mathrm{~m}$ quadrat at each location. The plant samples were oven-dried at $75^{\circ} \mathrm{C}$ for $72 \mathrm{~h}$ to obtain dry weights. Detailed data of the topsoil $(0-20 \mathrm{~cm})$, terrain, and vegetational characteristics along the transect are summarized in Table 1.
Table 1

Classical statistics for selected soil $(0-20 \mathrm{~cm})$ properties, site elevation (SE), and aboveground biomass (AGB) for 135 locations along the transect. BD, bulk density; Ks, saturated soil hydraulic conductivity; OC, organic carbon; SD, standard deviation; CV, coefficient of variation.

\begin{tabular}{|c|c|c|c|c|c|}
\hline Variable & Max & Min & Mean & SD & $\mathrm{CV}(\%)$ \\
\hline $\mathrm{BD}, \mathrm{g} \mathrm{cm}^{-3}$ & 1.7 & 1.2 & 1.4 & 0.1 & 9.0 \\
\hline $\mathrm{Ks}, \mathrm{mm} \min ^{-1}$ & 3.7 & 0.0 & 0.8 & 0.7 & 88.0 \\
\hline Clay, \% & 23.6 & 0.0 & 11.1 & 5.6 & 51.0 \\
\hline Silt, \% & 73.0 & 0.0 & 44.6 & 19.4 & 43.0 \\
\hline Sand, \% & 100.0 & 4.1 & 44.3 & 24.5 & 55.0 \\
\hline $\mathrm{OC}, \mathrm{g} \mathrm{kg}^{-1}$ & 10.7 & 0.5 & 3.7 & 1.8 & 48.0 \\
\hline $\mathrm{SE}, \mathrm{m}$ & 1259.0 & 1180.0 & 1218.1 & 19.8 & 2.0 \\
\hline $\mathrm{AGB}, \mathrm{g} \mathrm{m}^{-2}$ & 627.8 & 5.0 & 226.0 & 125.1 & 55.0 \\
\hline
\end{tabular}

\subsection{Assessment of the depth persistence of spatial patterns of SWS}

\subsubsection{Spearman's rank correlation}

The Spearman's rank correlation test was first introduced to identify the similarly of the overall spatial pattern of soil-water 
content (Vachaud et al., 1985). The Spearman's rank correlation coefficient, $r_{s}$, is calculated as:

$r_{s}=1-\frac{6 \sum_{i=1}^{n}\left(R_{i j}-R_{i j^{\prime}}\right)^{2}}{n\left(n^{2}-1\right)}$

where $R_{i j}$ and $R_{i j^{\prime}}$ are the ranks of the SWS observed at location $i$ in soil layers $j$ and $j^{\prime}$, respectively, and $n$ is the number of observations. A higher $r_{s}$ within a series of soil-water measurements indicates a higher degree of similarity between the measurements. That is, the closer $r_{s}$ is to 1 , the more similar the spatial pattern (Vachaud et al., 1985).

\subsubsection{Wavelet coherency analysis}

Wavelet coherency can identify the similarity of spatial patterns between two spatial series. It requires the calculation of a wavelet coefficient for both data series. Wavelet coefficients are identified using wavelet transformation at different scales and locations. Farge (1992) and Kumar and Foufoula-Georgiou (1997) provide detailed introductions describing wavelet transformation, and Grinsted et al. (2004) and Si and Zeleke (2005) describe wavelet coherency. We will present a basic procedure for obtaining wavelet coherency.

The wavelet coefficient, $W_{i}^{Y}(s)$ is calculated using a continuous wavelet transformation (CWT) for a SWS series of length $n\left(Y_{i}\right.$, $i=1,2,3, \ldots, n)$ with equal incremental distance $\delta x$. The CWT can be defined as the convolution of $Y_{i}$ with the scaled and normalized wavelet with the fast Fourier transformation (FFT) (Torrence and Compo, 1998):

$W_{i}^{Y}(s)=\sqrt{\frac{\delta x}{s}} \sum_{j=1}^{n} Y_{j} \psi\left[(j-i) \frac{\delta x}{s}\right]$

where $\psi[]$ is the mother wavelet function and $s$ is the scale. $W_{i}^{Y}(s)$ can be expressed as $a+i b$ where $a$ and $b$ are the real and imaginary components of $W_{i}^{Y}(s)$, respectively.

There are many types of mother wavelet functions. Among these, Morlet wavelet retaining the real and imaginary components of the wavelet coefficient allows the detection of both location-dependent amplitude and phase for different frequencies in the spatial series (Torrence and Compo, 1998) and can be expressed as:

$\psi(\eta)=\pi^{-1 / 4} e^{i \omega \eta-0.5 \eta^{2}}$

where $\omega$ is the dimensionless frequency and $\eta$ is the dimensionless space $(\eta=s / x)$. The Morlet wavelet $(\omega=6)$ is good for extracting features, because it provides a good balance between space and frequency localization.

The cross wavelet power spectrum at scale $s$ and location $i$ for two SWS spatial series can be calculated as:

$\left|W_{i}^{X Y}(s)\right|=\left|W_{i}^{X}(s) \overline{W_{i}^{Y}(s)}\right|$

where $W_{i}^{X}(s)$ and $W_{i}^{Y}(s)$ are the wavelet coefficients of SWS spatial series $X$ and $Y$, respectively, and $\overline{W_{i}^{Y}(s)}$ is the conjugate of $W_{i}^{Y}(s)$.

The wavelet coherency of two spatial series can be written as (Grinsted et al., 2004; Torrence and Webster, 1999):

$R_{i}^{2}(s)=\frac{\left|S\left(s^{-1} W_{i}^{X Y}(s)\right)\right|^{2}}{S\left(s^{-1}\left|W_{i}^{X}(s)\right|^{2}\right) S\left(s^{-1}\left|W_{i}^{Y}(s)\right|^{2}\right)}$

where $S$ is a smoothing operator and can be written as:

$S(W)=S_{\text {scale }}\left(S_{\text {space }}(W(s, \tau))\right)$

where $\tau$ indicates location, $S_{\text {scale }}$ indicates smoothing along the wavelet scale axis and $S_{\text {space }}$ indicates smoothing in spatial distance. The following smoothing function is the normalized real Morlet wavelet and has a similar footprint to the Morlet wavelet. The smoothing along locations thus can be expressed as:

$S_{\text {space }}(W(s, \tau))=\left.\sum_{k=1}^{N}\left(W(s, \tau) \frac{1}{s \sqrt{2 \pi}} \exp \left(-\frac{\left(\tau-x_{k}\right)^{2}}{2 s^{2}}\right)\right)\right|_{s}$

where $\frac{1}{s \sqrt{2 \pi}} \exp \left(-\frac{\tau^{2}}{2 s^{2}}\right)$ is the smoothing function, and $\exp \left(-2 s^{2} \omega^{2}\right)$ is the Fourier transformation of this function, where $\omega$ is the frequency (Si and Zeleke, 2005). Eq. (9) can be implemented with FFT and inverse FFT (IFFT) in terms of convolution theorem and then written as:

$S_{\text {space }}(W(s, x))=\operatorname{IFFT}\left(F F T(W(s, \tau))\left(\exp \left(-2 s^{2} \omega^{2}\right)\right)\right.$

The smoothing along the scales can thereby be written as:

$S_{\text {scale }}\left(W\left(s_{k}, x\right)\right)=\left.\frac{1}{2 m+1} \sum_{j=k-m}^{k+m}\left(S_{\text {space }}\left(W\left(s_{j}, x\right)\right) \prod\left(0.6 s_{j}\right)\right)\right|_{x}$

where $\prod$ is the rectangle function, and $m$ is the number of terms on each symmetrical half of the window. The factor 0.6 is the empirically determined scale decorrelation length for the Morlet wavelet (Si and Zeleke, 2005; Torrence and Compo, 1998).

\subsubsection{Significance testing}

The significance of the wavelet coherency can be tested against Gaussian white and red noise (Pardo-Iguzquiza and RodriguezTovar, 2000). For white noise, the spatial data series have independently and identically distributed datapoints that are not auto-correlated. For red noise, however, the points have values similar to those of nearby points, but dissimilar to those further apart (Biswas and Si, 2011b). Red noise is thus generally modeled as a univariate lag- 1 auto regressive (AR1) process (Torrence and Compo, 1998; Si and Farrell, 2004). Many soil properties, though, commonly exhibit red-noise-like behavior (Si and Farrell, 2004), such as soil-water content, Ks, and OC content. We treated red-noise-like behavior as the assumed background for statistical testing. Our null hypothesis was thus that the wavelet coherency of a measured soil-water series was not different from that of red noise.

For a given AR1 process with a lag-1 autocorrelation coefficient $r$, Monte Carlo simulation was used to generate 1000 realizations of one soil-water series, and the wavelet coherency of each realization was calculated. Therefore, 1000 wavelet coherency values were sorted into ascending order. The 950th wavelet coherency value at a scale and location gives the $95 \%$ confidence level at that scale and location (Si and Zeleke, 2005). Unlike Pearson correlations, the wavelet coherency can reflect relationships between variables at each scale and location rather than the overall relationship. The phase information in a wavelet coherency analysis can identify different relationships (such as positive or negative) at each scale and location.

Exploratory analysis was performed in Microsoft Office Excel (Microsoft Corporation Inc., Redmond, USA). Spearman's rank correlation analysis was performed with SPSS 16.0 (SPSS Inc., Chicago, USA). Wavelet coherency analysis was conducted using the MATLAB (The MathWorks Inc., Natick, USA) code written by Grinsted et al. (2004) and available at: http://www.pol.ac.uk/ home/research/waveletcoherence/.

\section{Results}

\subsection{Spatial patterns of SWS in the various soil layers}

During the non-growing season, SWS had similar spatial patterns among the soil depths along the transect (Fig. 3). Each 


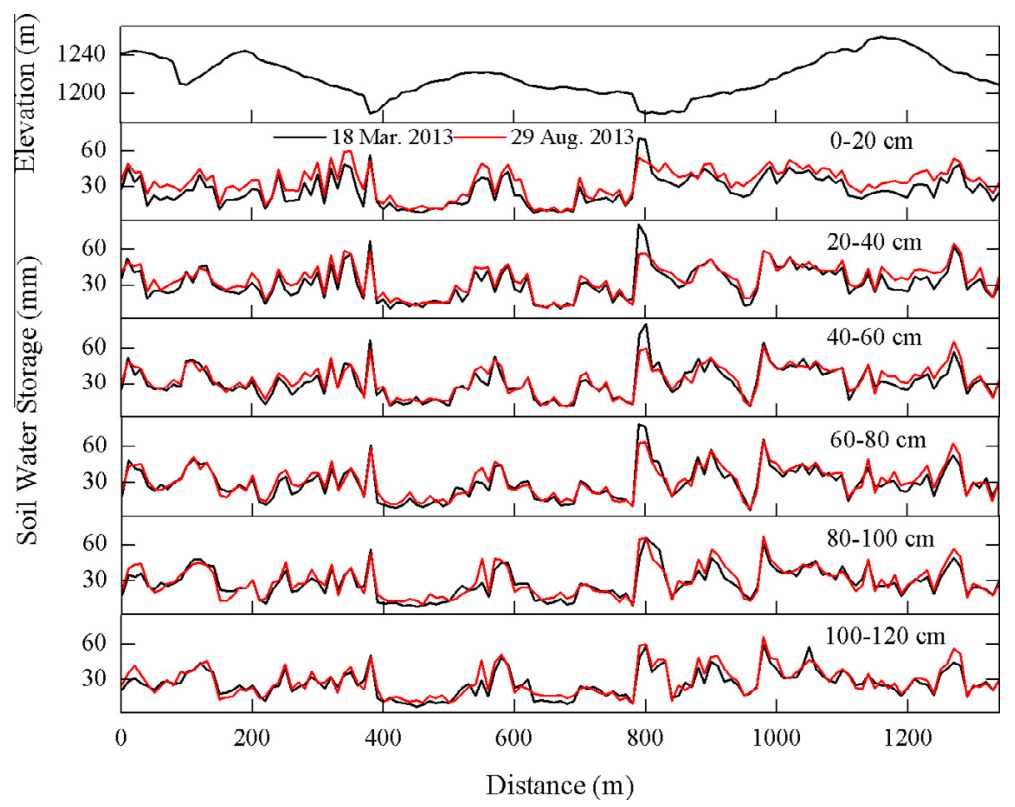

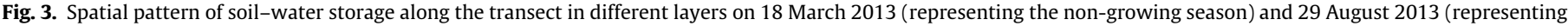
the growing season). The top panel indicates the site elevation (SE) along the transect.

layer had several strong peaks along the transect. These peaks were concentrated near the three gullies on the transect but also on slopes, such as at locations 590,980 , and $1270 \mathrm{~m}$ on the transect (Fig. 3). The SWS in the $0-20 \mathrm{~cm}$ layer on 21 January 2013 during the non-growing season ranged from 10.34 to $68.99 \mathrm{~mm}$, with a mean of $31.77 \mathrm{~mm}$. The mean SWS increased slightly from $31.77 \mathrm{~mm}$ in the $0-20 \mathrm{~cm}$ layer to $32.85 \mathrm{~mm}$ in the $20-40 \mathrm{~cm}$ layer and then gradually decreased to $27.27 \mathrm{~mm}$ in the $100-120 \mathrm{~cm}$ layer (Table 2). The standard deviation (SD) of the SWS ranged from $11.12 \mathrm{~mm}$ in the $100-120 \mathrm{~cm}$ layer to $13.97 \mathrm{~mm}$ in the $40-60 \mathrm{~cm}$ layer. The coefficient of variation (CV) of the SWS ranged from $39 \%$ in the $0-20 \mathrm{~cm}$ layer to $44 \%$ in the $60-80 \mathrm{~cm}$ layer. The data from other sampling dates during the non-growing season produced similar trends (Table 2). During the growing season, SWS had a similar spatial pattern in each layer, with some peaks along the transect (Fig. 3). These peaks were at the same places on 29 August 2013 as the peaks during the non-growing season (Fig. 3). The mean SWS increased from $33.45 \mathrm{~mm}$ in the $0-20 \mathrm{~cm}$ layer to $34.90 \mathrm{~mm}$ in the $20-40 \mathrm{~cm}$ layer and then decreased gradually to $28.47 \mathrm{~mm}$ in the $100-120 \mathrm{~cm}$ layer (Table 3). The SD of the SWS was very similar in each layer, ranging from $12.51 \mathrm{~mm}$ in the $40-60 \mathrm{~cm}$ layer to $12.97 \mathrm{~mm}$ in the $80-100 \mathrm{~cm}$ layer (Table 3 ). The CV of the SWS varied between $36 \%$ and $44 \%$ among the layers (Table 3).The mean SWS during the growing season, however, had increased from $16.34 \mathrm{~mm}$ in the $0-20 \mathrm{~cm}$ layer to $25.12 \mathrm{~mm}$ in the $100-120 \mathrm{~cm}$ layer by 15 June 2013 (Table 3). Compared with measurements on 29 August 2013, the mean SWS showed a similar trend on 30 July 2013 and 28 September 2013.

\subsection{Similarity in the overall spatial pattern of SWS in the various layers}

The Spearman's rank correlation coefficients identified an overall similarity of spatial patterns of SWS among the layers. The coefficients between every pair of depths for any sampling date were statistically significant $(P<0.01)$, indicating strong similarity in the spatial pattern of SWS between layers. $r_{s}$ decreased with increasing depth interval during both the non-growing (Table 4 ) and the growing (Table 5) seasons. $r_{s}$ ranged from 0.71
Table 2

Statistical summary of soil-water storage in the various layers for a measurement series during the non-growing season. SD, standard deviation; CV, coefficient of variation.

\begin{tabular}{|c|c|c|c|c|c|}
\hline Layer $(\mathrm{cm})$ & $\operatorname{Max}(\mathrm{mm})$ & $\operatorname{Min}(\mathrm{mm})$ & Mean $(\mathrm{mm})$ & $\mathrm{SD}(\mathrm{mm})$ & $\mathrm{CV}(\%)$ \\
\hline \multicolumn{6}{|c|}{21 January 2013} \\
\hline $0-20$ & 68.99 & 10.34 & 31.77 & 12.53 & 39 \\
\hline $20-40$ & 73.40 & 10.14 & 32.85 & 13.59 & 41 \\
\hline $40-60$ & 80.30 & 8.80 & 32.23 & 13.97 & 43 \\
\hline $60-80$ & 71.10 & 7.46 & 30.11 & 13.30 & 44 \\
\hline $80-100$ & 61.90 & 8.23 & 28.50 & 12.11 & 43 \\
\hline $100-120$ & 63.62 & 7.27 & 27.27 & 11.12 & 41 \\
\hline \multicolumn{6}{|c|}{24 February 2013} \\
\hline $0-20$ & 68.22 & 8.61 & 31.64 & 12.36 & 39 \\
\hline $20-40$ & 77.80 & 10.14 & 32.87 & 13.79 & 42 \\
\hline $40-60$ & 77.80 & 9.95 & 32.11 & 13.80 & 43 \\
\hline $60-80$ & 78.00 & 7.46 & 30.15 & 13.85 & 46 \\
\hline $80-100$ & 68.99 & 8.80 & 28.61 & 12.66 & 44 \\
\hline $100-120$ & 65.35 & 7.65 & 26.98 & 11.32 & 42 \\
\hline \multicolumn{6}{|c|}{18 March 2013} \\
\hline $0-20$ & 70.52 & 7.84 & 27.44 & 12.42 & 45 \\
\hline $20-40$ & 81.06 & 10.91 & 31.85 & 13.71 & 43 \\
\hline $40-60$ & 81.06 & 10.53 & 31.53 & 13.45 & 43 \\
\hline $60-80$ & 78.38 & 6.69 & 29.62 & 13.36 & 45 \\
\hline $80-100$ & 65.92 & 8.80 & 28.36 & 12.37 & 44 \\
\hline $100-120$ & 60.55 & 7.08 & 26.71 & 11.25 & 42 \\
\hline \multicolumn{6}{|c|}{16 April 2013} \\
\hline $0-20$ & 52.70 & 5.93 & 21.01 & 10.72 & 51 \\
\hline $20-40$ & 60.94 & 10.34 & 28.42 & 12.03 & 42 \\
\hline $40-60$ & 71.86 & 8.99 & 29.71 & 12.28 & 41 \\
\hline $60-80$ & 70.52 & 6.69 & 28.58 & 12.39 & 43 \\
\hline $80-100$ & 63.05 & 9.19 & 28.04 & 11.73 & 42 \\
\hline $100-120$ & 61.70 & 7.84 & 26.85 & 11.17 & 42 \\
\hline
\end{tabular}

to 0.95 during the non-growing season and from 0.62 to 0.97 during the growing season, with means of 0.85 and 0.83 , respectively.

\subsection{Similarities in the scales of spatial pattern of SWS in the layers}

Wavelet coherency analysis investigated the scale-specific correlations of SWS between the $0-20 \mathrm{~cm}$ layer and the other three layers. We divided the scales into three groups using the 
Table 3

Statistical summary of soil-water storage in the various layers for a measurement series during the growing season. SD, standard deviation; CV, coefficient of variation.

\begin{tabular}{|c|c|c|c|c|c|}
\hline Layer $(\mathrm{cm})$ & $\operatorname{Max}(\mathrm{mm})$ & $\operatorname{Min}(\mathrm{mm})$ & Mean $(\mathrm{mm})$ & $\mathrm{SD}(\mathrm{mm})$ & $\mathrm{CV}(\%)$ \\
\hline \multicolumn{6}{|c|}{15 June 2013} \\
\hline $0-20$ & 36.98 & 4.01 & 16.34 & 7.08 & 43 \\
\hline $20-40$ & 47.33 & 4.97 & 19.48 & 8.37 & 43 \\
\hline $40-60$ & 51.16 & 5.54 & 22.05 & 10.11 & 46 \\
\hline $60-80$ & 59.21 & 5.93 & 23.68 & 11.39 & 48 \\
\hline $80-100$ & 62.66 & 6.12 & 25.12 & 11.89 & 47 \\
\hline $100-120$ & 62.85 & 6.69 & 25.12 & 11.22 & 45 \\
\hline \multicolumn{6}{|l|}{30 July 2013} \\
\hline $0-20$ & 59.79 & 7.84 & 34.08 & 13.30 & 39 \\
\hline $20-40$ & 66.88 & 11.29 & 37.51 & 13.15 & 35 \\
\hline $40-60$ & 67.07 & 10.53 & 35.54 & 12.30 & 35 \\
\hline $60-80$ & 69.95 & 5.16 & 32.42 & 12.89 & 40 \\
\hline $80-100$ & 67.45 & 10.14 & 29.96 & 13.03 & 43 \\
\hline $100-120$ & 68.03 & 10.14 & 28.20 & 12.13 & 43 \\
\hline \multicolumn{6}{|c|}{29 August 2013} \\
\hline $0-20$ & 60.17 & 8.80 & 33.45 & 12.53 & 37 \\
\hline $20-40$ & 65.54 & 11.29 & 34.90 & 12.61 & 36 \\
\hline $40-60$ & 65.73 & 10.14 & 33.23 & 12.51 & 38 \\
\hline $60-80$ & 64.96 & 7.84 & 31.06 & 12.87 & 41 \\
\hline $80-100$ & 67.26 & 9.76 & 29.81 & 12.97 & 44 \\
\hline $100-120$ & 66.69 & 9.76 & 28.47 & 12.44 & 44 \\
\hline \multicolumn{6}{|c|}{28 September 2013} \\
\hline $0-20$ & 63.43 & 7.27 & 33.50 & 14.29 & 43 \\
\hline $20-40$ & 70.14 & 10.34 & 39.30 & 14.67 & 37 \\
\hline $40-60$ & 68.22 & 9.76 & 41.08 & 14.89 & 36 \\
\hline $60-80$ & 69.95 & 8.80 & 40.50 & 15.34 & 38 \\
\hline $80-100$ & 71.48 & 9.57 & 39.82 & 15.16 & 38 \\
\hline $100-120$ & 75.12 & 10.14 & 37.53 & 14.58 & 39 \\
\hline
\end{tabular}

Table 4

Spearman's rank correlation coefficients between the soil-water storages of the various layers during the non-growing season.

\begin{tabular}{|c|c|c|c|c|c|c|}
\hline Layer $(\mathrm{cm})$ & $0-20$ & $20-40$ & $40-60$ & $60-80$ & $80-100$ & $100-120$ \\
\hline \multicolumn{7}{|c|}{21 January 2013} \\
\hline $0-20$ & 1.00 & 0.91 & 0.79 & 0.77 & 0.76 & 0.73 \\
\hline $20-40$ & & 1.00 & 0.90 & 0.85 & 0.83 & 0.78 \\
\hline $40-60$ & & & 1.00 & 0.95 & 0.89 & 0.85 \\
\hline $60-80$ & & & & 1.00 & 0.94 & 0.89 \\
\hline $80-100$ & & & & & 1.00 & 0.95 \\
\hline $100-120$ & & & & & & 1.00 \\
\hline \multicolumn{7}{|c|}{24 February 2013} \\
\hline $0-20$ & 1.00 & 0.89 & 0.78 & 0.77 & 0.75 & 0.71 \\
\hline $20-40$ & & 1.00 & 0.91 & 0.87 & 0.84 & 0.77 \\
\hline $40-60$ & & & 1.00 & 0.95 & 0.88 & 0.82 \\
\hline $60-80$ & & & & 1.00 & 0.94 & 0.87 \\
\hline $80-100$ & & & & & 1.00 & 0.95 \\
\hline $100-120$ & & & & & & 1.00 \\
\hline \multicolumn{7}{|c|}{18 March 2013} \\
\hline $0-20$ & 1.00 & 0.91 & 0.80 & 0.79 & 0.77 & 0.73 \\
\hline $20-40$ & & 1.00 & 0.90 & 0.87 & 0.84 & 0.78 \\
\hline $40-60$ & & & 1.00 & 0.95 & 0.89 & 0.83 \\
\hline $60-80$ & & & & 1.00 & 0.94 & 0.88 \\
\hline $80-100$ & & & & & 1.00 & 0.95 \\
\hline $100-120$ & & & & & & 1.00 \\
\hline \multicolumn{7}{|c|}{16 April 2013} \\
\hline $0-20$ & 1.00 & 0.92 & 0.81 & 0.80 & 0.75 & 0.73 \\
\hline $20-40$ & & 1.00 & 0.91 & 0.88 & 0.84 & 0.78 \\
\hline $40-60$ & & & 1.00 & 0.95 & 0.88 & 0.82 \\
\hline $60-80$ & & & & 1.00 & 0.94 & 0.88 \\
\hline $80-100$ & & & & & 1.00 & 0.95 \\
\hline $100-120$ & & & & & & 1.00 \\
\hline
\end{tabular}

All correlations were significant at $P<0.001$.

similarities among the wavelet coherency graphs between any two depths for selected measurements. The three scale groups were small $(<40 \mathrm{~m})$, intermediate $(40-160 \mathrm{~m})$, and large $(>160 \mathrm{~m})$, respectively.
Table 5

Spearman's rank correlation coefficients between the soil-water storages of the various layers during the growing season.

\begin{tabular}{|c|c|c|c|c|c|c|}
\hline Layer $(\mathrm{cm})$ & $0-20$ & $20-40$ & $40-60$ & $60-80$ & $80-100$ & $100-120$ \\
\hline \multicolumn{7}{|c|}{15 June 2013} \\
\hline $0-20$ & 1.00 & 0.91 & 0.84 & 0.82 & 0.76 & 0.74 \\
\hline $20-40$ & & 1.00 & 0.93 & 0.89 & 0.83 & 0.79 \\
\hline $40-60$ & & & 1.00 & 0.97 & 0.90 & 0.86 \\
\hline $60-80$ & & & & 1.00 & 0.95 & 0.90 \\
\hline $80-100$ & & & & & 1.00 & 0.97 \\
\hline $100-120$ & & & & & & 1.00 \\
\hline \multicolumn{7}{|l|}{30 July 2013} \\
\hline $0-20$ & 1.00 & 0.91 & 0.77 & 0.72 & 0.68 & 0.66 \\
\hline $20-40$ & & 1.00 & 0.87 & 0.81 & 0.76 & 0.72 \\
\hline $40-60$ & & & 1.00 & 0.94 & 0.81 & 0.74 \\
\hline $60-80$ & & & & 1.00 & 0.91 & 0.84 \\
\hline $80-100$ & & & & & 1.00 & 0.96 \\
\hline $100-120$ & & & & & & 1.00 \\
\hline \multicolumn{7}{|c|}{29 August 2013} \\
\hline $0-20$ & 1.00 & 0.90 & 0.77 & 0.76 & 0.73 & 0.72 \\
\hline $20-40$ & & 1.00 & 0.90 & 0.86 & 0.82 & 0.79 \\
\hline $40-60$ & & & 1.00 & 0.96 & 0.89 & 0.84 \\
\hline $60-80$ & & & & 1.00 & 0.95 & 0.90 \\
\hline $80-100$ & & & & & 1.00 & 0.97 \\
\hline $100-120$ & & & & & & 1.00 \\
\hline \multicolumn{7}{|c|}{28 September 2013} \\
\hline $0-20$ & 1.00 & 0.90 & 0.79 & 0.74 & 0.69 & 0.62 \\
\hline $20-40$ & & 1.00 & 0.89 & 0.82 & 0.77 & 0.68 \\
\hline $40-60$ & & & 1.00 & 0.94 & 0.84 & 0.75 \\
\hline $60-80$ & & & & 1.00 & 0.93 & 0.83 \\
\hline $80-100$ & & & & & 1.00 & 0.92 \\
\hline $100-120$ & & & & & & 1.00 \\
\hline
\end{tabular}

All correlations were significant at $P<0.001$. (a) 0 to 20 vs 20 to $40 \mathrm{~cm}$

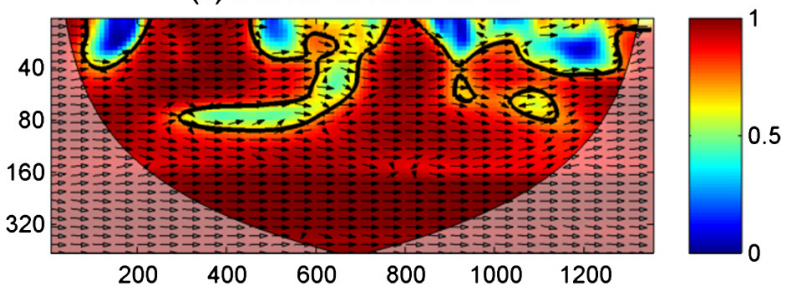

(b) 0 to 20 vs 60 to $80 \mathrm{~cm}$

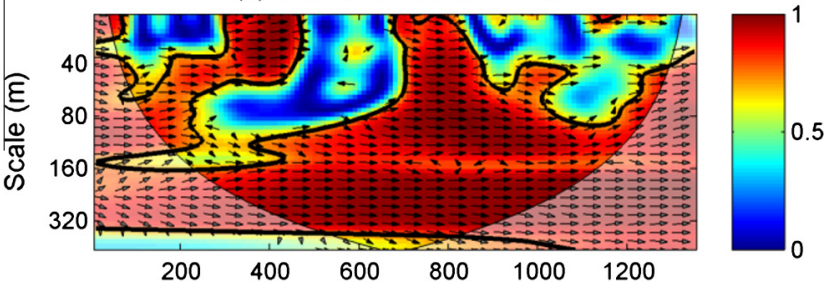

(c) 0 to 20 vs 100 to $120 \mathrm{~cm}$

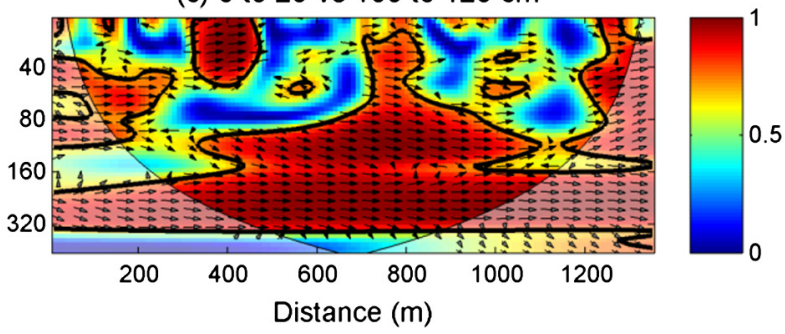

Fig. 4. Wavelet coherency of soil-water storage along the transect between (a) the 0 - to 20 and the 20 - to $40 \mathrm{~cm}$ layers, (b) the 0 - to 20 and the 60 - to $80 \mathrm{~cm}$ layers, and (c) the 0 - to 20 and the 100 - to $120 \mathrm{~cm}$ layers on 18 March 2013, representing the non-growing season. The $y$-axes are the scales. The color bars indicate the values of the wavelet coefficients, the solid black lines represent the $5 \%$ significance levels, and the arrows indicate the phase relationships. (For interpretation of the references to color in this figure legend, the reader is referred to the web version of this article.) 
On 18 March 2013 during the non-growing season, SWSs between the $0-20 \mathrm{~cm}$ and the other layers, including the $60-80$ and $100-120 \mathrm{~cm}$ layers, were significantly correlated at small scales at several locations (Fig. 4). SWSs between the 0-20 and $20-40 \mathrm{~cm}$ layers were significantly correlated at the intermediate scales across most of the transect, but correlations between the 0-20 and 100-120 cm layers were significant at limited locations (Fig. 4). For the scales of $160-320 \mathrm{~m}$, SWSs were significantly correlated between the $0-20 \mathrm{~cm}$ and the other layers along the transect (Fig. 4). On 29 August 2013 during the growing season, SWSs between the $0-20 \mathrm{~cm}$ and the deeper layers were significantly correlated at small scales at several locations (Fig. 5). For the intermediate scales, SWSs were significantly correlated across most of the transect between the $0-20$ and $20-40 \mathrm{~cm}$ layers but only at some locations between the $0-20 \mathrm{~cm}$ and the deeper (6080 and $100-120 \mathrm{~cm}$ ) layers (Fig. 5). SWSs between the $0-20 \mathrm{~cm}$ and the other three layers were significantly correlated along the entire transect at scales of $160-320 \mathrm{~m}$ (Fig. 5). The correlations of SWS between the $0-20 \mathrm{~cm}$ and the deeper layers at all scales along the entire transect were more similar for the growing than the non-growing season. The spatial patterns of SWS between the 0$20 \mathrm{~cm}$ and the deeper layers were similar for the other sampling dates during the non-growing and growing seasons.

We examined the wavelet coherency of SWS spatial patterns at the same layers between the two seasons (data for 18 March and 29 August 2013) (Fig. 6). Significantly correlated locations covered most of the transect intermittently at the small scales. Many locations of the transect were significantly correlated between

(a) 0 to 20 vs 20 to $40 \mathrm{~cm}$

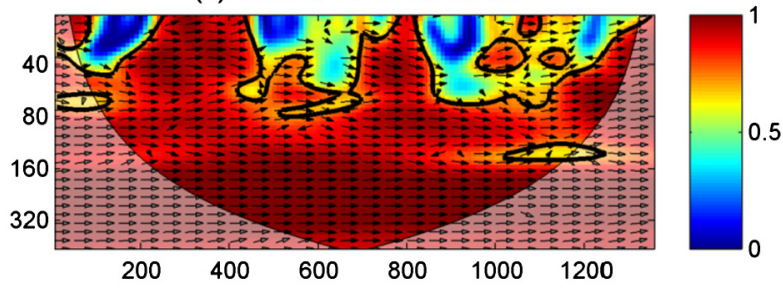

(b) 0 to 20 vs 60 to $80 \mathrm{~cm}$

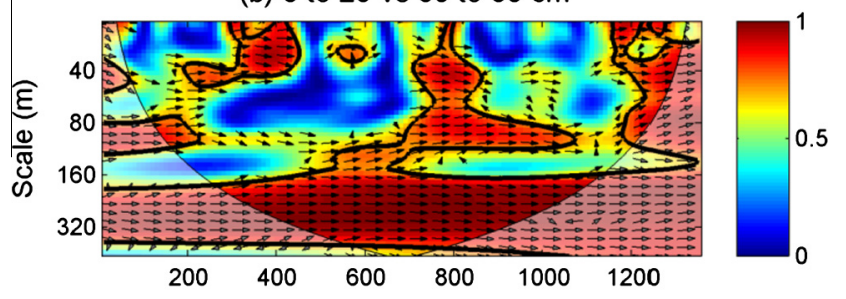

(c) 0 to 20 vs 100 to $120 \mathrm{~cm}$

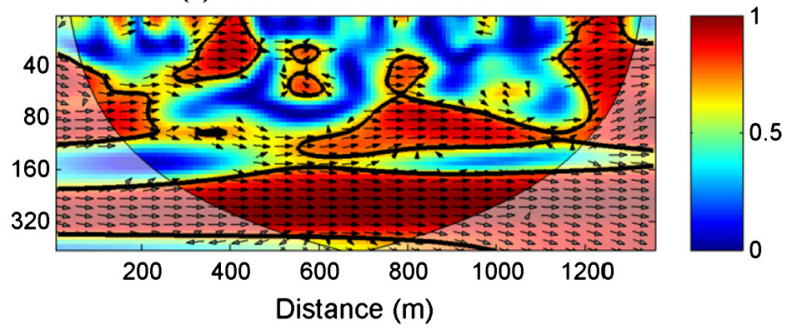

Fig. 5. Wavelet coherency of soil-water storage along the transect between (a) the 0 - to 20 and the 20 - to $40 \mathrm{~cm}$ layers, (b) the 0 - to 20 and the 60 - to $80 \mathrm{~cm}$ layers, and (c) the 0 - to 20 and the 100 - to $120 \mathrm{~cm}$ layers on 29 August 2013, representing the growing season. The $y$-axes are the scales. The color bars indicate the values of the wavelet coefficients, the solid black lines represent the $5 \%$ significance levels, and the arrows indicate the phase relationships. (For interpretation of the references to color in this figure legend, the reader is referred to the web version of this article.) seasons at the intermediate scales for the $0-20,60-80$, and 100 $120 \mathrm{~cm}$ layers in addition to locations between 300 and $700 \mathrm{~m}$ along the transect (Fig. 6). The SWSs were significantly correlated between seasons along the entire transect for the $20-40 \mathrm{~cm}$ layer at the intermediate scales and for all layers at large scales (Fig. 6). The wavelet coherency of SWS spatial patterns at the same layers between other selected dates during growing and nongrowing seasons showed the similar results.

The areas of significant correlations indicated the differences in wavelet coherency between the layers during the growing and non-growing seasons. The total area of significant correlation at the different scales generally decreased with increasing depth interval in both seasons (Figs. 4 and 5). The total area representing significant correlation between the same layers was higher for 18 March 2013 than 29 August 2013. The total area of significant correlation between the same layers in the different seasons, however, increased from the 0-20 to the 20-40 cm layer and then decreased with depth (Fig. 6). The directions of the wavelet coherency arrows in Figs. 7 and 8 indicate the type of correlation. Arrows pointing to the right of significant areas suggest an "in phase" relationship, or positive correlation. Arrows pointing to the left indicate an "out of phase" relationship, or negative correlation. SWS was thus correlated negatively with site elevation (Fig. 7) and positively with clay content (Fig. 8).

(a) 0 to $20 \mathrm{~cm}$ of 18 Mar. vs 0 to $20 \mathrm{~cm}$ of 29 Aug.

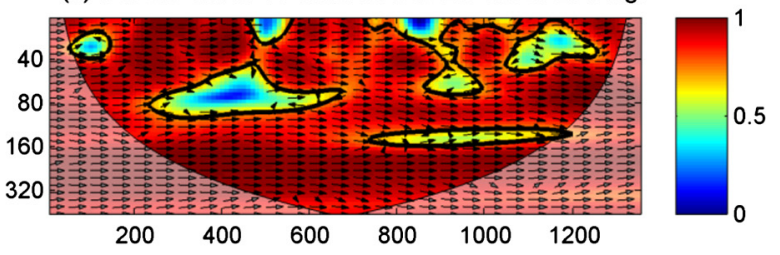

(b) 20 to $40 \mathrm{~cm}$ of 18 Mar. vs 20 to $40 \mathrm{~cm}$ of 29 Aug

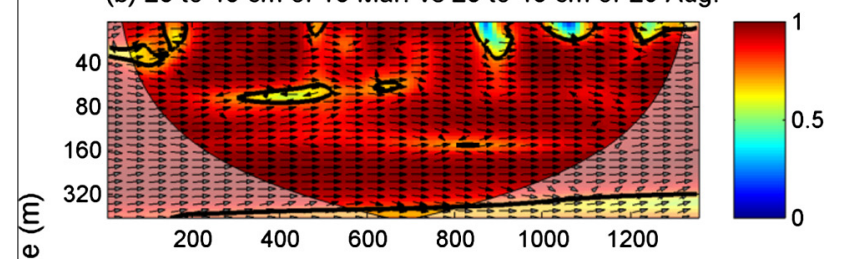

(c) 60 to $80 \mathrm{~cm}$ of $18 \mathrm{Mar}$. vs 60 to $80 \mathrm{~cm}$ of $29 \mathrm{Aug}$.

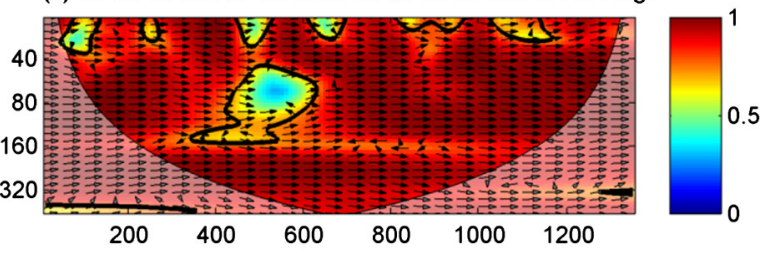

(d) 100 to $120 \mathrm{~cm}$ of 18 Mar. vs 100 to $120 \mathrm{~cm}$ of 29 Aug.

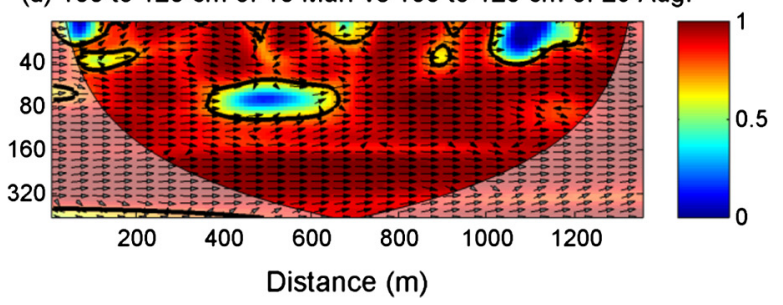

Fig. 6. Wavelet coherency of soil-water storage along the transect between the (a) 0-20, (b) 20-40, (c) 60-80, and (d) 100-120 cm layers for 18 March 2013 and 29 August 2013. The $y$-axes are the scales. The color bars indicate the values of the wavelet coefficients, the solid black lines represent the $5 \%$ significance levels, and the arrows indicate the phase relationships. (For interpretation of the references to color in this figure legend, the reader is referred to the web version of this article.) 
(a) 0 to $20 \mathrm{~cm}$ of 18 Mar. 2013 and Elevation
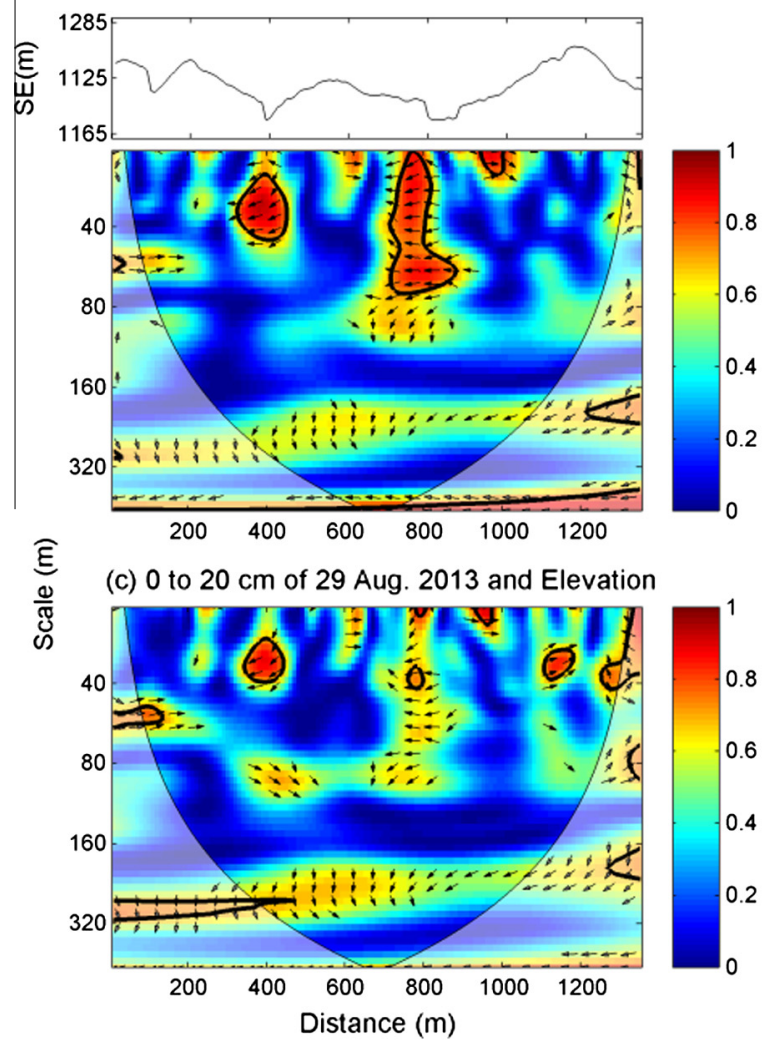

(b) 100 to $120 \mathrm{~cm}$ of 18 Mar. 2013 and Elevation
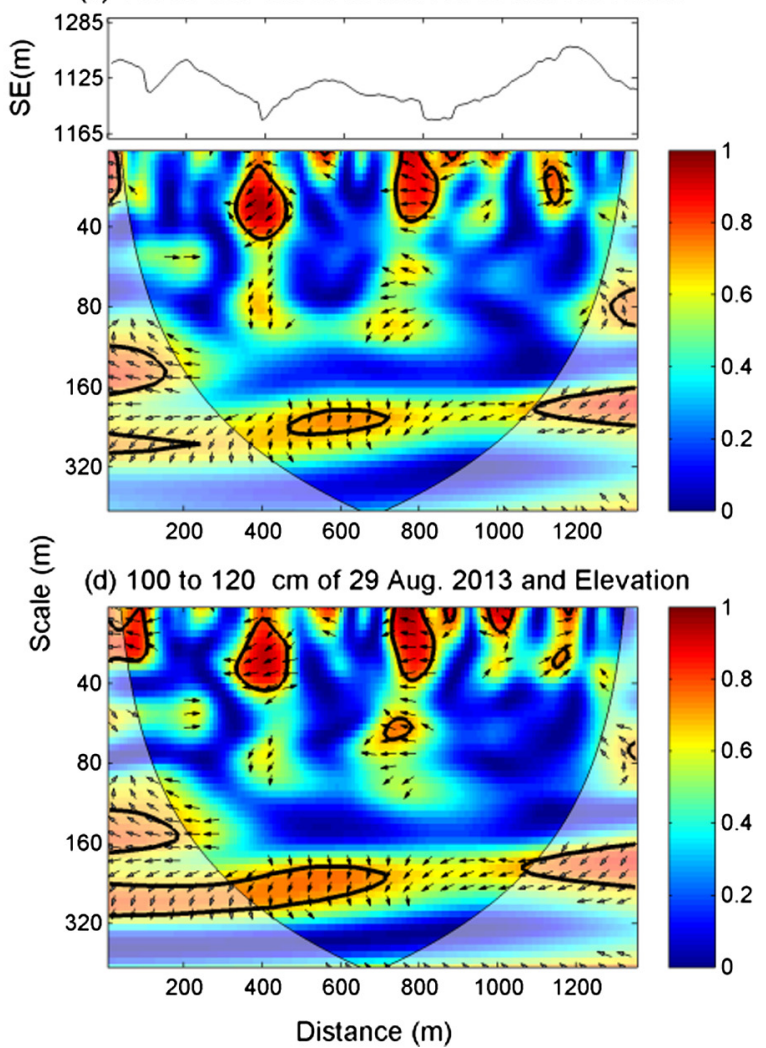

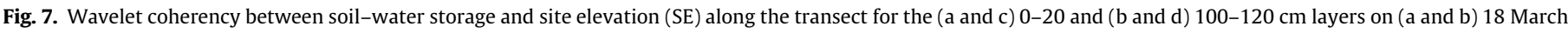

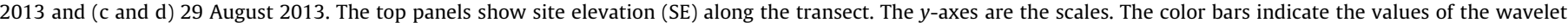

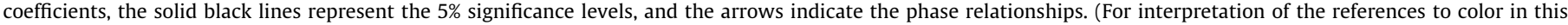
figure legend, the reader is referred to the web version of this article.)

\section{Discussion}

SWS fluctuated along the transect in each layer during both the non-growing and growing seasons. SWS had an obvious depth persistence within the profiles (Fig. 3). SWS peaked at different locations along the transect in the different seasons. The presence of peaks in the gullies, indicating the retention of more soil water, may be attributed to the position of the gullies in the landscape. Gullies always act as sinks in this semiarid area, accumulating water from hillslope runoff. The peaks in SWS on the slopes may be due to the soil texture. These locations may contain higher clay contents (Fig. 8). The similar trend of SWS along the profiles in the non-growing season indicated a higher temporal stability of SWS, but SWS varied among different sampling dates in the growing season. More than $70 \%$ of the annual precipitation falls in the growing season (Fig. 2), so the water is redistributed unevenly on the undulating landscape. The soil layers thus displayed different water statuses on different sampling dates. Plants, though, consume more than $70 \%$ of the water they need from the root zone (Feddes et al., 1978; Morris, 2006), which affects the soil-water dynamics. The SD and CV were similar among the layers, perhaps due to the similar meteorological conditions, topography, and soil texture. In addition, the CVs were moderately variable, based on the scale of Nelsen and Bouma (1985).

The overall spatial patterns between any two SWS series on selected sampling dates during different seasons were strongly similar, in accordance with the observations by Biswas and $\mathrm{Si}$ (2011a), Gao and Shao (2012a) and Jia et al. (2013b), perhaps because the soil layers had similar intrinsic soil properties such as texture and $\mathrm{OC}$ content or because the layers at the same location had similar hydrological conditions, such as infiltration, runoff, and evapotranspiration. In addition, the correlation coefficients decreased with distance between layers in both seasons. These results are in agreement with those from other studies (Arya et al., 1983; Tallon and Si, 2004; Pachepsky et al., 2005; Guber et al., 2008; Penna et al., 2009; Hu et al., 2009). The effects of climatic conditions (Hu et al., 2010), root activity (Cassel et al., 2000), and soil structure (Guber et al., 2003) on the SWS spatial patterns gradually decrease with depth. Other studies investigating the temporal stability of SWS spatial patterns using Spearman's rank correlations have reported similar results (Biswas and Si, 2011a; Gao and Shao, 2012b; Jia and Shao, 2013; Zhang and Shao, 2013). For example, Zhang and Shao (2013) found that soil-surface water content was more highly correlated between sampling series collected over a short period of time than over longer periods.

The significant coherency at all scales among the layers in the different seasons may be attributed to the soil texture. The significant scale dependence of SWS on clay content, especially at large scales, is shown in Fig. 8. Hu and Si (2013) and She et al. (2013) also found strong correlations between SWS and clay content using multivariate empirical mode decomposition at larger scales. They attributed these correlations to the higher influence of particle size on SWS at larger scales. The difference in elevation along the transect was large (1056-1130 m), but SWS was not significantly correlated with site elevation, except at a few locations at small scales (Fig. 7). These results did not agree with those by Biswas and Si (2011a). Biswas and Si (2011a) found a significant relationship between SWS and elevation in a hummocky landscape, even though the difference in elevation was $<5 \mathrm{~m}$. Knolls and depressions in hummocky landscapes can retain soil water 
(a) 0 to $20 \mathrm{~cm}$ of 18 Mar. 2013 and Clay
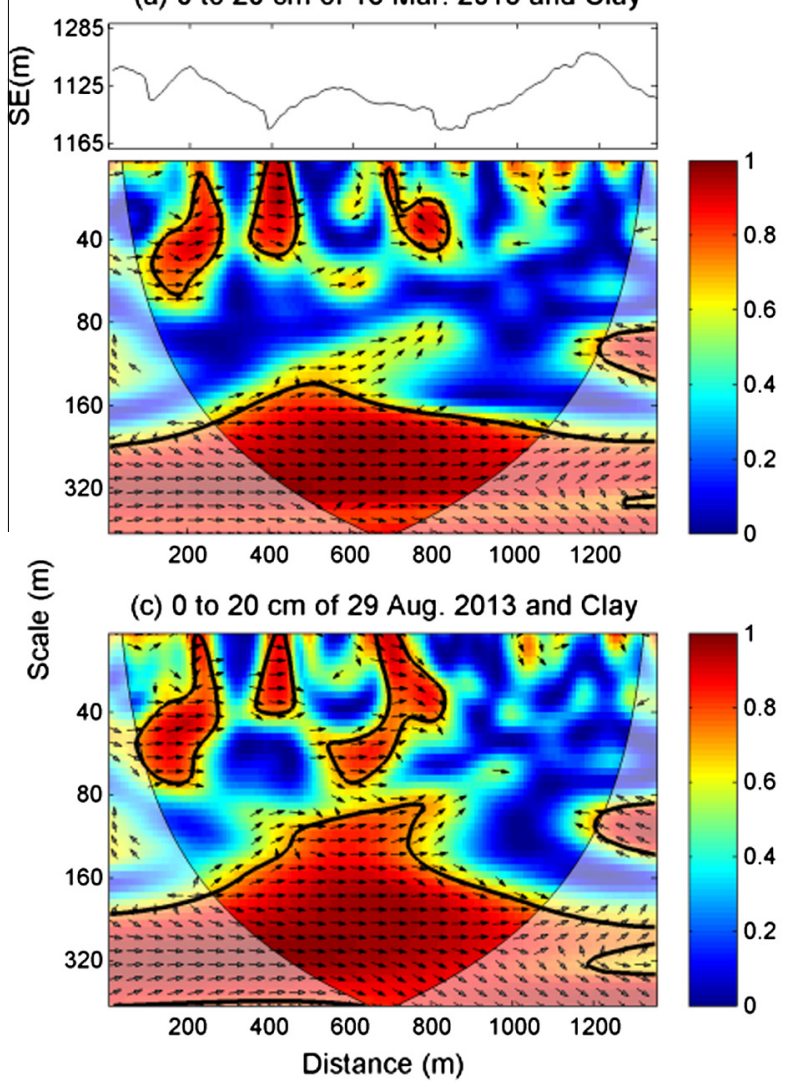

(b) 100 to $120 \mathrm{~cm}$ of 18 Mar. 2013 and Clay
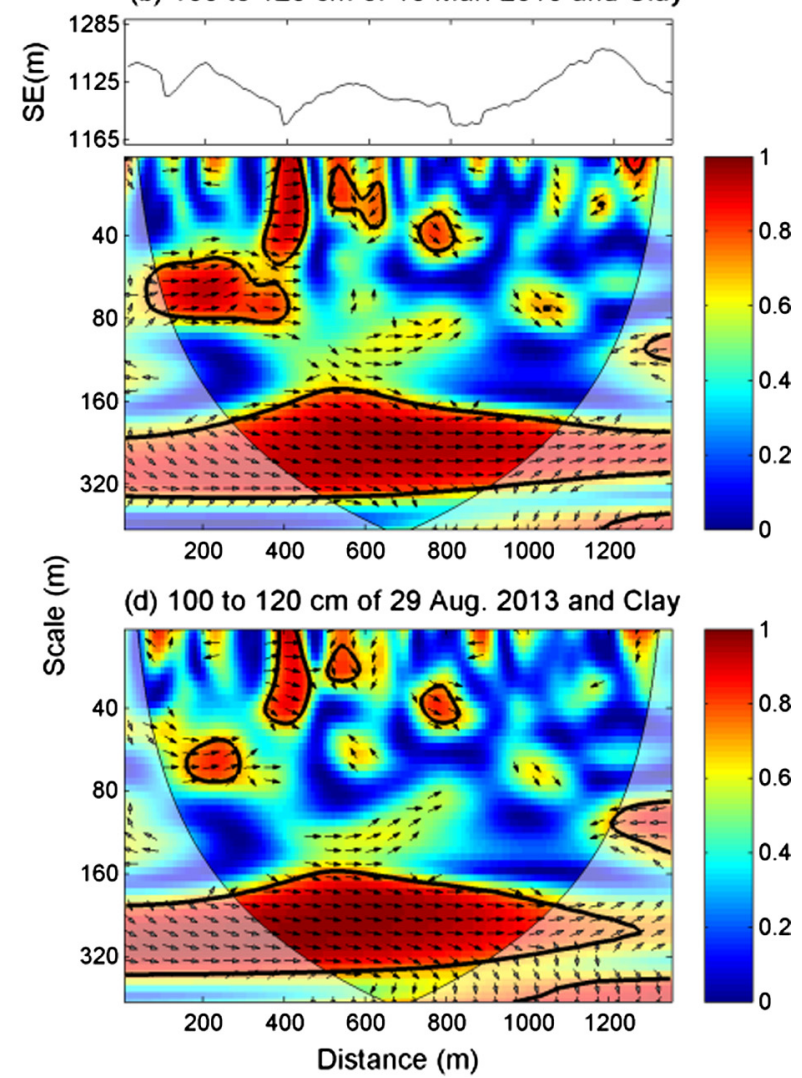

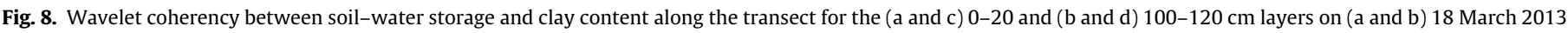

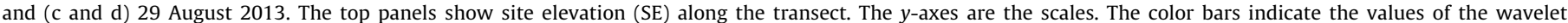

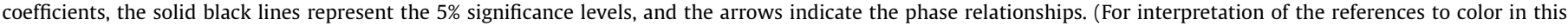
figure legend, the reader is referred to the web version of this article.)

well, so terrain factors that can affect wavelet coherency between soil layers consist mainly of variations in landform elements and microtopography. The total area of significant coherency at the different scales in our study generally decreased between surface and subsurface layers with increasing depth interval for the different seasons (Figs. 4 and 5). These results indicated a reduction in the degree of depth persistence in SWS spatial patterns and supported the results of the Spearman's rank correlation analysis. Biswas and Si (2011a) also found that the similarity gradually decreased with distance between the surface and subsurface layers for both recharge and discharge periods. The decrease in our study in the total area of significant coherency from the non-growing to the growing season suggested a reduction in the degree of depth persistence (Figs. 4 and 5), perhaps due to the use of water by the vegetation and/or to the higher precipitation in the growing season, which could affect important hydrological processes, such as evapotranspiration and infiltration, and could change the water storage along the soil profile. The total areas of significant correlation between the same layers in different seasons were large, indicating a high range of SWS temporal stability from the non-growing to the growing season, in agreement with the findings by Biswas and Si (2011c) and Hu et al. (2014). Hu et al. (2014) found that a temporally stable location for estimating the mean SWS in a season of one year could be applied to the same season of another year. The area of significant correlation between the $0-20$ and 20$40 \mathrm{~cm}$ layers in our study was larger than that between the 0-20 and $100-120 \mathrm{~cm}$ layers during the same season (Figs. 4 and 5). In contrast, the area of significant correlation between the $0-20 \mathrm{~cm}$ layers between seasons was not significantly different from that of other layers (Fig. 6). We may thus conclude that soil depth had a larger effect than season on the similarities in SWS spatial patterns.

The depth persistence in the SWS spatial patterns between the surface and deeper layers can be used to estimate soil-water content in deeper layers. Measuring the water content only in the surface soil would reduce costs and resources (Biswas and Si, 2011a) and would also provide information necessary for adopting dataassimilation techniques for integrating remote sensing and soilwater modeling (Houser et al., 1998; Walker et al., 2001; Heathman et al., 2003). The depth persistence of SWS within soil profiles could also be incorporated into hydrological models, be applied to water management, and contribute to our understanding of the hydrological dynamics of landscapes.

\section{Conclusions}

We investigated the similarities in SWS spatial patterns between surface and deeper soil layers during different seasons using Spearman's rank correlation and wavelet coherency analyses. The following conclusions can be drawn.

(1) Spatiotemporal analysis showed that the temporal evolution of SWS profiles differed between the growing and the non-growing seasons due to the complex effects of controlling factors such as soil texture, terrain, vegetation, and climate. 
(2) Significant correlations were observed between any two soil layers during both seasons, and the correlation coefficients decreased with distance between layers.

(3) The significant coherency of SWS spatial patterns between layers may be attributed to clay content at large scales during different seasons.

(4) The total area of significant coherency decreased from the non-growing to the growing season, suggesting a reduction in the degree of depth persistence. Soil depth had a higher effect than season on the depth persistence of the SWS spatial patterns.

\section{Acknowledgement}

This study was financially supported by the National Natural Science Foundation of China (Nos. 51179180 and 41390463). Special thanks go to C.L. Zhao for his zealous help in data collection.

\section{References}

Arya, L.M., Richter, J.C., Paris, J.F., 1983. Estimating profile water storage from surface zone soil moisture measurements under bare field conditions. Water Resour. Res. 19, 403-412.

Biswas, A., Si, B.C., 2011a. Depth persistence of the spatial pattern of soil water storage in a hummocky landscape. Soil Sci. Soc. Am. J. 75, 1099-1109.

Biswas, A., Si, B.C., 2011b. Identifying scale specific controls of soil water storage in a hummocky landscape using wavelet coherency. Geoderma 165, 50-59.

Biswas, A., Si, B.C., 2011c. Scales and locations of time stability of soil water storage in a hummocky landscape. J. Hydrol. 408, 100-112.

Brocca, L., Melone, F., Moramarco, T., Morbidelli, R., 2009. Soil moisture temporal stability over experimental areas in Central Italy. Geoderma 148, 364-374.

Brocca, L., Melone, F., Moramarco, T., Morbidelli, R., 2010. Spatial-temporal variability of soil water and its estimation across scales. Water Resour. Res. 46. W02516.

Cassel, D.K., Wendroth, O., Nielsen, D.R., 2000. Assessing spatial variability in an agricultural experiment station field: opportunities arising from spatial dependence. Agron. J. 92, 706-714.

Cosh, M.H., Jackson, T.J., Moran, S., Bindlish, R., 2008. Temporal persistence and stability of surface soil moisture in a semi-arid watershed. Remote Sens. Environ. 112, 304-313.

Entin, J.K., Robock, A., Vinnikov, K.Y., Hollinger, S.E., Liu, S., Namkhai, A., 2000. Temporal and spatial scales of observed soil moisture variations in the extratropics. J. Geophys. Res. 105, 11865-11877.

Farge, M., 1992. Wavelet transform and their applications to turbulence. Annu. Rev. Fluid Mech. 24, 395-457.

Feddes, R.A., Kowalik, P.J., Zaradny, H., 1978. Simulation of Field Water Use and Crop Yield. Halsted Press, John Wiley \& Sons Inc., New York.

Gao, L., Shao, M.A., 2012a. Temporal stability of shallow soil water content for three adjacent transects on a hillslope. Agric. Water Manage. 110, 41-54.

Gao, L., Shao, M.A., 2012b. Temporal stability of soil water storage in diverse soil layers. Catena 95, 24-32.

Gao, X.D., Wu, P.T., Zhao, X.N., Shi, Y.G., Wang, J.W., 2011. Estimating spatial meansoil water contents of sloping jujube orchards using temporal stability. Agric. Water Manage. 102, 66-73.

Grayson, R.B., Blöschl, G., Western, A.W., McMahon, T.A., 2002. Advances in the use of observed spatial patterns of catchment hydrological response. Adv. Water Resour. 25, 1313-1334.

Grayson, R.B., Western, A.W., 1998. Towards areal estimation of soil water content from point measurements: time and space stability of mean response. J. Hydrol. 207, 68-82.

Grinsted, A., Moore, J.C., Jevrejeva, S., 2004. Application of cross wavelet transform and wavelet coherence to geophysical time series. Nonlinear Proc. Geoph. 11, 561-566.

Guber, A.K., Gish, T.J., Pachepsky, Y.A., van Genuchten, M.T., Daughtry, C.S.T., Nicholson, T.J., Cady, R.E., 2008. Temporal stability of estimated soil water flux patterns across agricultural fields. Int. Agrophys. 22, 209-214.

Guber, A.K., Rawls, W.J., Shein, E.V., Pachepsky, Y.A., 2003. Effect of soil aggregate size distribution on water retention. Soil Sci. 168, 223-233.

Heathman, G.C., Starks, P.J., Ahuja, L.R., Jackson, T.J., 2003. Assimilation of surface soil moisture to estimate profile soil water content. J. Hydrol. 279, 1-17.

Hébrard, O., Voltz, M., Andrieux, P., Moussa, R., 2006. Spatio-temporal distribution of soil surface moisture in a heterogeneously farmed Mediterranean catchment. J. Hydrol. 329, 110-121.

Houser, P.R., Shuttleworth, W.J., Famiglietti, J.S., Gupta, H.V., Syed, K.H., Goodrich, D. C., 1998. Integration of soil moisture remote sensing and hydrologic modeling using data assimilation. Water Resour. Res. 34, 3405-3420.

Hu, W., Biswas, A., Si, B.C., 2014. Application of multivariate empirical mode decomposition for revealing scale-and season-specific time stability of soil water storage. Catena 113, 377-385.
Hu, W., Shao, M.A., Wang, Q.J., Reichardt, K., 2009. Time stability of soil water storage measured by neutron probe and the effects of calibration procedures in a small watershed. Catena 79, 72-82.

Hu, W., Shao, M.A., Wang, Q.J., Reichardt, K., Tan, J., 2010. Watershed scale temporal stability of soil water content. Geoderma 158, 181-198.

Hu, W., Si, B.C., 2013. Soil water prediction based on its scale-specific control using multivariate empirical mode decomposition. Geoderma 193-194, 180-188.

Jacobs, J.M., Mohanty, B.P., Hsu, E.C., Miller, D., 2004. SME02: field scale variability, time stability and similarity of soil moisture. Remote Sens. Environ. 92, $436-446$

Jia, X.X., Shao, M.A., Wei, X.R., 2012. Responses of soil respiration to N addition, burning and clipping in temperate semiarid grassland in northern China. Agri. Forest Meteor. 166-167, 32-40.

Jia, X.X., Shao, M.A., Wei, X.R., Wang, Y.Q., 2013a. Hillslope scale temporal stability of soil water storage in diverse soil layers. J. Hydrol. 498, 254-264.

Jia, Y.H., Shao, M.A., 2013. Temporal stability of soil water storage under four types of revegetation on the northern Loess Plateau of China. Agric. Water Manage. 117, 33-42.

Jia, Y.H., Shao, M.A., Jia, X.X., 2013b. Spatial pattern of soil moisture and its temporal stability within profiles on a loessial slope in northwestern China. J. Hydrol. 495, 150-161

Kachanoski, R.G., de Jong, E., 1988. Scale dependence and the temporal persistence of spatial patterns of soil-water storage. Water Resour. Res. 24, 85-91.

Klute, A., Dirksen, C., 1986. Hydraulic conductivity of saturated soils. In: Klute, A. (Ed.), Methods of Soil Analysis. ASA and SSSA, Madison, Wisconsin, USA, pp 694-700.

Koster, R.D., Dirmeyer, P.A., Guo, Z., Bonan, G., Chan, E., Cox, P., Gordon, C.T., Kanae, S., Kowalczyk, E., Lawrence, D., Liu, P., Lu, C.H., Malyshev, S., McAvaney, B., Mitchell, K., Mocko, D., Oki, T., Oleson, K., Pitman, A., Sud, Y.C., Taylor, C.M., Verseghy, D., Vasic, R., Xue, Y., Yamada, T., 2004. Regions of strong coupling between soil moisture and precipitation. Science 305, 1138-1140. http://dx.doi. org/10.1126/science.1100217.

Kumar, P., Foufoula-Georgiou, E., 1997. Wavelet analysis of geophysical applications. Rev. Geophys. 35, 385-412.

Lin, H., 2006. Temporal stability of soil moisture spatial pattern and subsurface preferential flow pathways in the shale hills catchment. Vadose Zone J. 5, 317-340.

Liu, B.X., Shao, M.A., 2014. Estimation of soil water storage using temporal stability in four land uses over 10 years on the Loess Plateau, China. J. Hydrol. 517, 974-984.

Mohanty, B.P., Skaggs, T.H., 2001. Spatio-temporal evolution and time-stable characteristics of soil moisture within remote sensing footprints with varying soil, slope, and vegetation. Adv. Water Resour. 24, 1051-1067.

Morris, M., 2006. Soil Moisture Monitoring: Low Cost Tools and Methods Publication number IP277. <http://attra.ncat.org/attra-pub/soil_moisture. html> (verified 13 April 2011). ATTRA-National Sustainable Agriculture Information Service, Butte, MT.

Nelson, D.R., Bouma, J., 1985. Soil Spatial Variability. Pudoc, Wageningen.

Nelson, D.W., Sommers, L.E., 1982. Total carbon, organic carbon and organic matter In: Page, A.L., Miller, R.H., Keeney, D.R. (Eds.), Methods of Soil Analysis. Part 2. Agronomy Monograph, second ed. ASA and SSSA, Madison, WI, pp. 534-580.

Pachepsky, Y.A., Guber, A.K., Jacques, D., 2005. Temporal persistence in vertical distributions of soil moisture contents. Soil Sci. Soc. Am. J. 69, 347-352.

Pardo-Iguzquiza, E., Rodriguez-Tovar, F.J., 2000. The permutation test as a nonparametric method for testing the statistical significance of power spectrum estimation in cyclostratigraphic research. Earth Planet. Sci. Lett. 181, 175-189.

Penna, D., Borga, M., Norbiato, D., Dalla Fontana, G., 2009. Hillslope scale soil moisture variability in a steep alpine terrain. J. Hydrol. 364, 311-327.

She, D.L., Liu, D.D., Peng, S.Z., Shao, M.A., 2013. Multiscale influences of soil properties on soil water content distribution in a watershed on the Chinese Loess Plateau. Soil Sci. 178, 530-539.

Si, B.C., Farrell, R.E., 2004. Scale dependent relationships between wheat yield and topographic indices: a wavelet approach. Soil Sci. Soc. Am. J. 68, 577-588.

Si, B.C., Zeleke, T.B., 2005. Wavelet coherency analysis to relate saturated hydraulic properties to soil physical properties. Water Resour. Res. 41, W11424.

Starks, P.J., Heathman, G.C., Jackson, T.J., Cosh, M.H., 2006. Temporal stability of soil moisture profile. J. Hydrol. 324, 400-411.

Tallon, L.K., Si, B.C., 2004. Representative soil water benchmarking for environmental monitoring. J. Environ. Inform. 4, 31-39.

Torrence, C., Compo, G.P., 1998. A practical guide to wavelet analysis. Bull. Am. Meteorol. Soc. 79, 61-78.

Torrence, C., Webster, P.J., 1999. Interdecadal changes in the ENSO-monsoon system. J. Clim. 12, 2679-2690.

Vachaud, G., Passerat de Silans, A., Balabanis, P., Vauclin, M., 1985. Tempora stability of spatially measured soil water probability density function. Soil Sci. Soc. Am. J. 49, 822-828.

Walker, J.P., Willgoose, G.R., Kalma, J.D., 2001. One-dimensional soil moisture profile retrieval by assimilation of near-surface observations: a comparison of retrieval algorithms. Adv. Water Resour. 24, 631-650.

Wang, Y.Q., Shao, M.A., Liu, Z.P., Warrington, D.N., 2012. Regional spatial pattern of deep soil water content and its influencing factors. Hydrolog. Sci. J. 57, 265-281.

Wang, Y.Q., Shao, M.A., Shao, H.B., 2010. A preliminary investigation of the dynamics characteristics of dried soil layers on the Loess Plateau of China. J. Hydrol. 381, 9-17.

Western, A.W., Grayson, R.B., Blöschl, G., 2002. Scaling of soil moisture: a hydrologic perspective. Annu. Rev. Earth Planet. Sci. 30, 149-180. 
Western, A.W., Zhou, S.L., Grayson, R.B., McMahon, T.A., Blöschl, G., Wilson, D.J. 2004. Spatial correlation of soil moisture in small catchments and its relationship to dominant spatial hydrological processes. J. Hydrol. 286, $113-$ 134.

Yates, T.T., Si, B.C., Farrell, R.E., Pennock, D.J., 2007. Time, location, and scale dependence of soil nitrous oxide emission, water, and temperature using wavelet coherency analysis. J. Geophys. Res. 112, D09104.
Zhang, P.P., Shao, M.A., 2013. Temporal stability of surface soil moisture in a desert area of northwestern China. J. Hydrol. 505, 91-101.

Zhao, Y., Peth, S., Wang, X.Y., Lin, H., Horn, R., 2010. Controls of surface soil moisture spatial patterns and their temporal stability in a semi-arid steppe. Hydrol. Process. 24, 2507-2519. 